\title{
La población de Caracas (1754-1820). Estructura y características
}

\author{
Lila Mago de Chópite \\ Centro de Investigaciones Históricas \\ Mario Briceño-Iragorry. Caracas, Venezuela
}

\begin{abstract}
Nos proponemos en este artículo determinar fases o momentos en el desarrollo histórico de la población de Santiago de León de Caracas y establecer las relaciones con la estructura y dinámica del espacio urbano desde mediados del siglo XVIII hasta comienzos del siglo XIX. Las partes consideradas son las siguientes: la primera, destinada al estudio de las matrículas parroquiales o padrones eclesiásticos de la ciudad de Santiago de León de Caracas, análisis y valoración de estas fuentes, aportes, ventajas y limitaciones en la reconstrucción del proceso histórico; y la segunda, dedicada al análisis de la estructura de la población específicamente entre los años 1772 y 1815, compuesta por españoles, negros libres, negros esclavos e indios y sus relaciones con el espacio urbano integrado por las parroquias eclesiásticas: Catedral, San Pablo, Candelaria y Altagracia.
\end{abstract}

\section{Matrículas parroquiales de la ciudad de Santiago de León de Caracas (1754-1820)}

La herramienta fundamental de esta investigación es la fuente primaria; es decir, los documentos originales. Con la ventaja de que este tipo de fuente, por su carácter cuantitativo, está menos expuesta a las dificultades de la subjetividad y los prejuicios y errores de interpretación a los que con frecuencia nos enfrentamos los que realizamos el difícil oficio de investigador, sobre la base de documentos que recogen hechos del pasado reciente. No quiere esto decir que escapemos, en el caso concreto de estas fuentes, a los problemas de la complejidad del hecho histórico y a las dificultades de su reconstrucción. Trataremos en este análisis de su valoración, exactitud y significación.

Las matrículas parroquiales son fuentes de inestimable valor que permiten a la demografía histórica la reconstrucción del proceso demográfico de poblaciones históricas, a través de la información directa y original de los hechos sociales que regían las relaciones entre la Iglesia y la feligresía de la parroquia eclesiástica en la sociedad colonial.

Estas fuentes constituyen los únicos censos de población colonial realizados de manera constante y permanente por las autoridades eclesiásticas, sobre todo a partir del año 1754 — según los registros depositados en el Archivo Arzobispal de Caracas- cuando la Iglesia Católica, a través de la 
legislación emanada de obispos, Concilios y Sinodales, ordena un mayor control de su población eclesiástica.

En el año 1687, en el Sínodo celebrado en Caracas, con asistencia de las autoridades eclesiásticas más importantes de ciudades, pueblos, valles, villas y demás lugares del Obispado, se establecieron las finalidades de la Iglesia en la sociedad colonial recogidas en las llamadas Constituciones Sinodales del Obispado de Venezuela y Santiago de León de Caracas. ${ }^{1}$

Desde esa fecha, según esta legislación, la Iglesia acordó la obligación de aplicar la matrícula o padrón, según una constitución en la cual se lee lo siguiente:

"Se empezará a hacer matrícula desde la Dominica Septuagésima, dividiéndose por barrios, asentando con distinción cada casa, el dueño de ella, el nombre de su mujer, e hijos, y los que son de confesión sola, y los de comunión: Advirtiendo que no hay persona exenta, por de oficio que no haya de matrícularse: y asimismo los encarcelados, para que envíemos quien los confiese y se les lleve el Señor, para cumplir con la Iglesia: y al recoger las cédulas, las deben dar todas, pues siendo católicos, han de ser iguales en el cumplimiento por lo mandado por Nuestra Santa Madre Iglesia y la dicha matrícula ha de servir para recoger las cédulas; y al fin de ella certificasen los curas que las hicieron aquel año, con todo cuidado y que no hay mas parroquianos de los contenidos en ella; afirmándolo in verbo sacerdotis; y la presentaren ante más, o vuestros provisores; y en los demás lugares ante nuestros vicarios; con apercibimiento que presentaremos contra ellos, con las penas que parecieren; y de la misma suerte, si no vinieren dichas matrículas con la claridad que mandamos". ${ }^{2}$

Respecto a otras obligaciones de la Iglesia, el Sínodo acordó todo lo referente a bienes raíces, censos, derechos, diezmos, etc. para evitar pérdidas económicas. Convertida la Iglesia en el único agente financiero de la economía colonial venezolana, se convierte también en el poder económico más importante que dirige los distintos grupos sociales que forman la sociedad colonial. ${ }^{3}$

1 Hechas en la Santa Iglesia Catedral de dicha ciudad de Caracas en el año del Señor de 1687. Por el Ilustrísimo y Reverendísimo Señor Doctor Don Diego de Baños y Sotomayor, Obispo de dicho Obispado, del Consejo de su Majestad, su Predicador y Capellán de Honor, etc. y aprobadas por la Majestad del Rey Don Carlos II, Año de 1693. Reimpresas en el Reinado del Señor Don Carlos Tercero, Año de 1761, siendo Obispo el Ilustrísimo Señor Don Diego Antonio Diez Madroñero. Con las Licencias necesarias. En Madrid. En la Imprenta de Joseph Rico, Impresor del Real y Supremo Consejo de Indias. Véase en Troconis de Veracoechea, Ermila: Los Censos en la Iglesia Colonial Venezolana. Caracas, 1982, tomo I, págs. 59-60.

2 Academia Nacional de la Historia. Constituciones Sinodales de la Diócesis de Santiago de León de Caracas, Tomo I, pág. 166. Véase en Farías, José Luis: "Las Matrículas y los Problemas de Historia Económica colonial en Venezuela". Revista Tierra Firme, núm. 16, Caracas, octubre-diciembre de 1986, año 4. Vol. 4, págs. 537-538.

3 Troconis de Veracoechea: Los censos..., pág. 69. 
La función de la Iglesia Católica como poder espiritual crea, a su vez, las bases ideológicas y políticas del poder temporal, en una comunidad de intereses con la Corona, con manifestaciones de poder en atención a la jerarquía política y económica; es el caso de los Virreinatos en la realidad social americana. Todas las actividades económicas que realizaba la población, giraban en torno a la Iglesia. Su injerencia se advierte tanto en las actividades agrícolas y pecuarias, eje de la vida económica, como en los otros aspectos de la vida social. Los libros de bautismo y entierros de blancos, indios, pardos y negros, son fuentes inagotables de la actividad social y cultural de la Iglesia. Hospitales, hospicios, casas de misericordia, escuelas y colegios, recibían ayuda y supervisión de la Iglesia.

La ayuda económica era posible gracias a los beneficios en las operaciones comerciales a través de los censos y obras pías ${ }^{4}$ administradas por conventos y cofradías, y por otros medios como donativos y cobros de bautizos, matrimonios, entierros, misas y rezos que se hacían en las parroquias.

Las matrículas o padrones eclesiásticos, punto central de este análisis, recogen la síntesis de la organización familiar dentro de la sociedad colonial: el empadronamiento por casas, número de personas que las habitan, grupo étnico-social al que corresponden, estado civil, sexo y otras consideraciones de interés para la investigación histórica.

La aplicación de la matrícula eclesiástica, como ya hemos visto, obedece a una disposición proveniente del Sínodo de Santiago de León de Caracas en 1687, en íntima relación con otros acuerdos que se hicieron en las ya mencionadas Constituciones Sinodales, como es el caso de los diezmos y primicias.

Quedó establecido por diezmo:

"Diezmo, según la común sentencia de los Doctores, es la décima parte de los frutos que se da a los Ministros de la Iglesia y por el ministerio espiritual que ejercita, se les debe; con lo cual hace el pueblo cristiano un obsequio a Dios, reconociéndole por autor de todos sus beneficios".

Con respecto a los vecinos que no pagaren los diezmos, se acordó lo siguiente:

4 Entiéndase aquí por Censo el "crédito hipotecario dado por una institución o particular (Conventos, Cofradías, Iglesia parroquial, Colegio Universidad, etc.), la cual entregaba cierta suma de dinero en efectivo a un solicitante, con la garantía de un bien hipotecado: hacienda, hato, vivienda, etc. En ciertos casos la entrega podía no ser en efectivo, sino en inmuebles. Ibídem, pág. 20. 


\section{LILA MAGO DE CHÓPITE}

"Y así son grandes y graves las amenazas y castigos que Dios ha hecho y hace a los que quebrantan tan justo precepto, dejando de pagar, retardando o pagando con disminución los diezmos que deben a su Deidad e Iglesias; pues es conforme a razón que sirviendo los Ministros de ella al pueblo cristiano, el pueblo les debe corresponder con la congrua sustentación de que viven y se mantienen las fábricas en que se celebra el Divino Culto". ${ }^{5}$

También se legisló sobre el castigo que debía imponérsele a quien no cumpliera las disposiciones establecidas. Se aplicaba la excomunión mayor a los infractores y se les privaba de la sepultura eclesiástica.

En cuanto a la primicia se estableció el siguiente concepto:

"Las primicias son principios de los frutos que da la tierra y se consagran a Dios, los cuales tienen obligación de pagar todos los feligreses a sus propios párrocos en la iglesia en donde son parroquianos.

La diferencia que hay entre diezmos y primicias es esta: que los diezmos se deben de diez, uno; la primicia se debe del primer fruto, y más sazonado, en que de ordinario suele ser defraudado el Derecho Parroquial. Páguese la primicia de todo género de granos, según la costumbre de este Obispado, de siete medidas, una". ${ }^{6}$

El significado de estos dos conceptos ratifica el control tan estricto que ejercía la Iglesia sobre su feligresía, así como también el valor económico que tenía la aplicación de los mismos. El Sínodo dejó claramente estipulado quiénes debían pagar este tipo de renta, es decir, "Todos los fieles cristianos, de los frutos que Dios les diere".

Los diezmos debían ser pagados de las haciendas que tuvieren propias o arrendadas; de las heredades, haciendas patrimoniales, estancias de ganado, etc. Afectaba a los clérigos seculares, los monasterios de Regulares, los caballeros de las Ordenes Militares, mayordomos y trabajadores libres que poseyeran algún tipo de labranza, igualmente, los esclavos que en ciertos días sembraban sus pegujales (porción de tierra cedida por su amo para ser labrada por él con derecho a obtener los beneficios), o los que tenían hornos de cal, teja o ladrillo. Pagaban asimismo "todas las personas que hurtaren cualquier fruto de tierras o ganados, o hicieren o causaren daños o pérdidas en ellos, lo cual se ha de regular pagando a los dueños de las haciendas las nueve partes y a la Iglesia, que tenía derecho a dicho diezmo, la una". Los indios también pagaban el diezmo "de todo fruto que les queda de sus labores". Con respecto a éstos últimos, antes del Sínodo el diez-

5 Constituciones Sinodales. Libro 4. Tomo XXIII, pág. 385, en Ibídem, pág. 62.

6 Constituciones Sinodales. Tomo XXIV, pág. 399, en Ibídem, págs. 64-65. 
mo se convierte en un impuesto indirecto que pagaban a través del encomendero, deducido de los beneficios recibidos del trabajo de aquéllos.

Al suprimirse el servicio personal de la encomienda, los indios, en vez de pagar el impuesto a su encomendero, debían pagarlo directamente a la Iglesia, sin rebajar el diezmo del producto de la gran hacienda beneficiado con el servicio de la mano de obra esclava o indígena.?

La matrícula parroquial o censo eclesiástico era el principal instrumento legal que permitía el cobro efectivo de esta tributación. Los registros se realizaban anualmente, entre los meses de mayo y junio, de acuerdo con lo dispuesto en las Constituciones Sinodales del año 1687 y a partir de 1800 con arreglo al mandato del rey en su real orden de 25 de julio de ese mismo año. ${ }^{8}$

De acuerdo con esta disposición, en las matrículas de esos años se asienta la siguiente información:

"Número de sus feligreses con división de castas, sexos y estados... con arreglo a lo mandado por el Rey nuestro señor en su Real Orden del 25 de Julio de 1800; a lo dispuesto en su consecuencia por el ilustrísimo Señor (de buena memoria) primero Arzobispo que fue de esta Metrópoli”.

A continuación se expresa:

"Y en cumplimiento de las Constituciones Sinodales de este arzobispado, y órdenes posteriores de los ilustrísimos Señores Obispos, de esta Diócesis".

Obsérvese, una vez más, la cooperación mutua entre la Corona y la Iglesia en el cumplimiento de esta obligación, y la importancia de estos registros, que exigían un estricto control de la feligresía por parroquias eclesiásticas.

Es nuestro interés resaltar la importancia del estudio y análisis de estos documentos en la reconstrucción del proceso demográfico de la ciudad de Santiago de León de Caracas en su contexto histórico social, en un período caracterizado por la ausencia de otras fuentes fiables que permitan la cuantificación de los datos.

7 Ibídem, págs. 63-64.

8 Matrícula de la parroquia Catedral (Parte poniente) Año 1758. En esta matrícula aparecen una información sobre diezmos cuyo total asciende al mismo número de feligreses que es de 3.870 .

9 Archivo Arzobispal de Caracas (en adelante, AAC). Sección Matrículas Parroquiales. Caracas-Altagracia. Carpeta, núm. 2. Matrícula de la Parroquia de Santa María de Altagracia de esta ciudad de Caracas, año 1807, fol. 704 
La población de Caracas, sin embargo, fue estimada por cronistas, visitantes, funcionarios del rey y de la Iglesia. A mediados del siglo XVIII Joseph Luis de Cisneros calculó para Caracas un vecindario compuesto de 26.340 almas. ${ }^{10}$

En 1772 el obispo Mariano Martí, en su famoso censo con motivo de su visita pastoral a la diócesis de Caracas, dio un total de 18.669 habitantes, correspondiente a la suma de las cuatro parroquias que integraban el plano urbano de Santiago de León de Caracas: Catedral, San Pablo, Nuestra Señora de Altagracia y Nuestra Señora de la Candelaria. ${ }^{11}$ La diferencia entre Cisneros y Martí es bastante notoria.

Se hicieron otros cálculos igualmente importantes. En 1783 el Censo de Castro y Araóz arrojó una cifra de 29.022 habitantes, ${ }^{12}$ con una diferencia a favor de 10.353 respecto al censo de Martí. Para el año 1792, según los datos asentados en las matrículas parroquiales de la población de Caracas, ésta era de 28.362 habitantes. Si comparamos con las estimaciones de Castro y Araóz, la población disminuyó, con una diferencia de 660 habitantes en el transcurso de nueve años; pero con respecto a las cifras de Martí hubo un aumento de 9.693 en veinte años.

Finalizando el período colonial, el sabio naturalista alemán Alejandro de Humboldt calculó unos 40.000 habitantes para Caracas en 1800. Depons, en 1802, daba la cifra de 42.000 habitantes; y en 1812 Codazzi elevó esta cantidad a 50.000 .

Los datos que hemos obtenido de los asientos de las matrículas eclesiásticas presentan una notable diferencia con las cifras antes mencionadas. Nos inclinamos a confiar más en los datos localizados en los documentos eclesiásticos, por la secuencia de los mismos y las razones de fiabilidad que ya han sido expuestas.

El análisis de las matrículas parroquiales nos permite establecer la estructura de la población dividida en categorías étnico-sociales, por sexo, estado civil y otras consideraciones de interés histórico que pueden contribuir a la reconstrucción del proceso demográfico de Caracas durante el período colonial. Los resultados parciales, por parroquias y por años, nos facilitaron la elaboración de matrices de la población total, con la utilización de variables demográficas que permitieron determinar el ritmo de crepág. 121.

10 Cisneros, Joseph Luis de: Descripción exacta de la Provincia de Venezuela. Caracas, 1981,

11 Mago de Chópite, Lila: Caracas y su Crecimiento Urbano. Caracas, 1986, págs. 82-83.

12 Ibídem: Caracas y su..., pág. 85. 
cimiento y las tendencias de la población de acuerdo a la continuidad de los datos localizados.

\section{Aportes a la investigación histórica}

Las matrículas eclesiásticas constituyen la fuente más importante para la reconstrucción del proceso de desarrollo social y urbano de la ciudad de Caracas en tiempos coloniales, y permiten establecer la relación entre la organización espacial y la población.

El espacio estaba organizado por el Cabildo, órgano del gobierno local, y permaneció bajo la supervisión de este organismo, en cuanto a la distribución geográfica de las actividades productivas que separaban los límites de la ciudad propiamente dicha de sus alrededores. Le correspondió al Cabildo la asignación de tierras llamadas solares (urbanos), peonías y caballerías (rurales), que se otorgaban a los primeros conquistadores y pobladores.

La Iglesia, convertida en otro de los grandes propietarios de tierra durante el régimen de dominación colonial, llegó a poseer una gran propiedad territorial, administrada por el poder eclesiástico. Es de su control exclusivo todo lo referente a la distribución de la población por parroquias eclesiásticas, en completa concordancia con las ordenanzas municipales en lo que respecta a la organización de la ciudad, nomenclatura y otras medidas urbanas sobre la construcción de viviendas y prestación de servicios.

Los cambios operados en el desarrollo urbano que se observan en las secuencias de las matrículas parroquiales, asociados con los cambios demográficos y socio-culturales, constituyen los aportes más importantes para la reconstrucción del proceso histórico que caracteriza a la sociedad caraqueña durante la dominación colonial. A través de ellas puede obtenerse información de la organización espacial, topografía, actividades económicas, nomenclatura eclesiástica, número y estado de las viviendas, estructura social, instituciones culturales, etc., datos que constituyen la base fundamental del historiador interesado en realizar estudios de historia local y regional.

Los datos obtenidos, organizados y analizados, permiten la reconstrucción del plano de la ciudad, dividida en parroquias, cuyo centro de relaciones era la iglesia parroquial, alrededor de la cual giraban muchas de las actividades de la vida cotidiana, en cuanto al suministro de los servicios del 
culto católico, instrucción elemental y superior, obras sociales, centros de salud (hospitales), limosnas y obras de caridad.

En el año 1766 el obispo ilustrísimo señor don Diego Antonio Diez Madroñero, ordenó la elaboración del plano de Caracas para una mejor organización eclesiástica por parroquias. Este plano se ajustó al modelo tradicional desde los tiempos del gobernador don Juan de Pimentel (1578); es decir, cuadricular con cinco calles de norte a sur y cinco calles de este a oeste.

El plano se conoce con el nombre de Plano de la Ciudad Mariana de Caracas, dedicado a Dios, su Santísimo Hijo, Santísima Madre y Santos Protectores de sus casas y vecinos. ${ }^{13}$ Esta organización corresponde al primer intento de dotar a Caracas de una nomenclatura sistematizada bajo la dirección del gobierno eclesiástico del citado obispo, quien se propuso convertir Caracas en una auténtica ciudad convento y cambiar muchas de las costumbres y hábitos de sus pobladores por el rezo colectivo y continuo en capillas y hogares. El 3 de enero de 1766 decretó, con el apoyo del gobernador don Felipe de Ricardo y de la mayoría de la aristocracia caraqueña, el plano de Nuestra Señora Mariana de Caracas, donde las calles — señaladas con el número romano recibieron los nombres de los episodios de la Vida, Pasión, Muerte y Resurrección de Jesucristo; las cuadras — señaladas en números arábigos — adoptaron los nombres relativos a las distintas advocaciones de la Madre de Dios; y las casas, los nombres de los Santos Patronos. ${ }^{14}$

En 1772 la ciudad de Caracas, de acuerdo a los datos de las matrículas parroquiales, estaba organizada en 4 parroquias: Catedral (Oriente y Poniente), San Pablo, Altagracia y Candelaria. Según los datos que arroja el censo eclesiástico realizado por el obispo Mariano Martí, sus habitantes sumaban un total de 18.669. Se estableció la demarcación de los límites de la ciudad y la separación de los pueblos vecinos, quedando igualmente marcados los límites de las parroquias eclesiásticas y lo correspondiente al número de calles, cuadras y casas, de norte a sur y de oriente a poniente, en atención a la ubicación en el plano previamente establecido.

Del análisis de estos datos asentados con extrema minuciosidad, en cumplimiento de las disposiciones del obispo y demás autoridades ecle-

13 Arellano Moreno, Antonio: Caracas, su Evolución y su Régimen Legal. Madrid, 1972, págs. 65-67. Léase también Rafael Valeri S.: "La Nomenclatura Caraqueña”. Boletín Histórico, núm. 40. Caracas, 1976, págs. 165-181.

14 Mago de Chópite, Lila: Caracas y su..., pág. 76 
siásticas podemos reconstruir, haciendo uso del análisis histórico en su concepción global y totalizadora de la realidad social, el pasado de la sociedad colonial caraqueña.

\section{Ventajas y limitaciones del uso de estas fuentes}

Tomando en consideración las matrículas referidas a Caracas, centro de atención de nuestro estudio, el trabajo de investigación de archivo sobre ellas nos permite señalar las siguientes ventajas y limitaciones en el uso de las mismas:

I) La población censada para fines de la organización de la Iglesia, como pago de diezmos, suministros de los servicios eclesiásticos, etc., corresponde a la feligresía católica empadronada por parroquias, incluyendo barrios, cantones, ranchos, haciendas y terrenos despoblados. Esta población, totalizada por parroquias, proporciona datos importantes para la elaboración de matrices por año, que permiten, a su vez, estimar la población general por año en la medida que se obtiene la información de todas las parroquias en determinados períodos, los cuales nos sirven de hitos en la reconstrucción del proceso de crecimiento de la población y de desarrollo urbano de la ciudad de Caracas de fines de siglo XVIII y de una parte del siglo XIX, hasta la instauración de la república.

II) Resulta difícil precisar si, además de esta población católica empadronada, pudiera existir un número escasamente reducido de personas herejes, ateos, judíos, árabes y luteranos, los cuales no participaban del culto católico; así como también de extranjeros, que se encontraban de paso por la capital por razones políticas, militares, etc. Sin embargo, las matrículas recogen algunas aclaratorias; sobre el particular nos remitimos a una de ellas que aparece en la matrícula de la parroquia Catedral, parte oriente, del año 1799:

"Y han dado cédulas del cumplimiento de los preceptos de confesión y comunión respectivamente a excepción de los que se han hallado ausentados de los que se tiene causa pendiente y otros que están reconvenidos sobre cuyo cumplimiento velare, como también sobre la reconciliación de los luteranos de los que se ha ausentado uno de esta feligresía". ${ }^{15}$

15 AAC, Matrículas Parroquiales. Caracas-Catedral, núm. 15. Matrícula de la Parroquia Catedral (Parte Oriente) Año 1799, fol. 700. 
En la matrícula correspondiente al año anterior se hace referencia a la reconciliación de tres herejes que deseaban su conversión, pero que la falta del conocimiento del idioma castellano, dificultaba conocer el grado de instrucción que tenían, impidiendo que se les otorgase; así mismo a otros extranjeros, que decían ser católicos; pero la misma falta del idioma obstaculizaba su aceptación en la práctica del sacramento de la confesión.

A este respecto consideramos, que la falta de información más precisa sobre el particular, no afecta los resultados ni las estimaciones, bastantes fiables, que arrojan los datos; esta población, por lo que se deduce del análisis de los documentos, debió ser muy escasa. Hay que tener en cuenta, por una parte, los fuertes controles ejercidos por la Corona sobre las personas que viajaban a las colonias americanas; y por otra parte, el estado de sumisión y otros mecanismos ideológicos que ejerció la Iglesia Católica, no solamente sobre los españoles sino también sobre la población esclava y aborigen.

Consideramos que, desde el punto de vista demográfico, estas dudas por falta de información más precisa no invalidan los resultados, si se tiene en cuenta que no disponemos de otra documentación. Le corresponde a la demografía histórica aclarar estas dudas mediante la localización y trabajos de otras fuentes.

III) Las limitaciones en el uso de estas fuentes están dadas por la falta de continuidad de los datos y las distintas modalidades que adoptaban los curas párrocos responsables de la elaboración de las matrículas; sobre todo en las primeras, que abarcan un período desde 1754 a 1780. En lo que respecta a éstas, la gran mayoría se conserva en buen estado, con número de folios completo, etc. Se lleva un estricto y minucioso control del número de sus habitantes por casas, incluyendo esclavos, indios, agregados y visitantes, formando parte de una auténtica comunidad familiar. Al final, los datos no aparecen discriminados por clases, por lo que se requiere el conteo cuidadoso. Esta labor resulta bastante tediosa y necesita de mucho tiempo para llevarla a cabo, sin riesgo de cometer errores. En la mayoría de ellas aparece la población discriminada según el cumplimiento de los preceptos religiosos: por lo que se refiere al número de personas con confesión y comunión, de sólo confesión y el número de párvulos, así como también se menciona el número de locos y bozales.

A partir del año 1781, la información es más ordenada en cuanto a elementos estructurales de la población. El resumen discrimina por grupos: eclesiásticos, blancos, mulatos y negros. En los años siguientes se agregan 
nuevos datos en los totales: sexo, estado civil, incluyendo el total de viudos y viudas, niños, catecúmenos y luteranos.

De 1800 en adelante, la matrícula se representa en un cuadro resumen, con una información cuyos datos no ofrecen variaciones notables en los años subsiguientes. Los datos expresados en la matriz representan las siguientes columnas: castas, que incluyen, colocados verticalmente, los siguientes grupos socio-raciales: blancos, indios, pardos libres, negros libres y esclavos; estos rubros se corresponden con los otros de las demás columnas horizontales: hombres casados, mujeres casadas, hombres solteros, mujeres solteras, párvulos, párvulas, totales.

La información obtenida sobre el crecimiento de la población por grupos étnico-sociales, su localización por parroquias, el surgimiento de nuevas viviendas, la formación de caseríos en la periferia, la construcción de barrios en áreas marginales y arrabales pobres, la instalación de nuevas unidades de producción — trapiches, carbonerías, comercios, conucos, etc.constituyen elementos de gran utilidad para la elaboración de cartas geohistóricas que permiten captar con mayor claridad el proceso integral, en su dimensión temporal-espacial, cuyos cambios permanentes recogidos en cartas sucesivas, por períodos, proporcionan un recurso válido para la comprensión de la dinámica espacial y socio-cultural, como también los otros factores que han participado en todo el proceso.

En cuanto a la composición por edades y sexo, la información resulta incompleta y sin continuidad, por lo que el solo uso de estas fuentes, imposibilita al historiador a usar reglas propias de la demografía, para determinar las tasas de fecundidad, natalidad y mortalidad.

En el caso de la parroquia Catedral (Oriente y Poniente), en 1807 localizamos una matrícula de sumo interés, por ser la única en su estilo en todos los años consultados, donde la población se divide por sexo, edades y grupos sociales. ${ }^{16}$ Las limitaciones de esta fuente, están dadas por los grupos o categorías de edades consideradas: de 0 a 16 años, de 16 a 40 y de 40 años en adelante.

De acuerdo a los datos extraídos pudimos establecer las siguientes relaciones: de 8.380 personas que representan el total, 5.073 son hembras, (60.54\%), el resto son varones, es decir, 3.307 (39.46\%). Primera observación: dominan las hembras sobre los varones. Este fenómeno es típico en todo el período que hemos trabajado, lo que demuestra que la mortalidad

16 Ibídem. Matrícula de la Parroquia de la Santa Iglesia Catedral de Caracas. Año 1807, fol. 521. 
es más elevada en el hombre que en la mujer; esto pudimos comprobarlo en los registros de párvulas y párvulos, donde los primeros siempre son mayores que los segundos. Debemos considerar otros elementos importantes: la emigración de hombres por razones económicas y políticas, mayores riesgos y peligros y su menor resistencia a las enfermedades.

Por otra parte pudimos considerar, respecto al primer grupo, que de las 8.380 personas censadas, 2.669 tienen edades comprendidas entre $0 \mathrm{y}$ 16 años $(31.85 \%), 1.421$ son hembras y 1.248 son varones. Este grupo incluye a la población infantil, sin embargo, tenemos algunas reservas para denominarla como tal, sobre todo en el caso de las mujeres; en esa edad tope, 16 años, muchas mujeres ya estaban casadas y con hijos; en los hombres, sin embargo, era menos frecuente.

En el segundo grupo de 8.380 personas, 3.691 tenían las edades comprendidas entre 16 y 40 años (44.00\%), 2.290 hembras y 1.401 varones. Este porcentaje corresponde a la población en capacidad reproductiva.

En el tercer grupo la relación es la siguiente: de 8.380 personas, 2.020 tienen edades comprendidas entre 40 y más (24.10\%), 1.362 hembras y 658 varones. En este grupo resulta difícil precisar el número de personas que podían pasar de 40 a 50 o más años; si se tiene en cuenta que la expectativa de vida para el siglo XVIII estaba entre 35 y 40 años, el número de personas de más de 50 años no debió ser muy alto.

En síntesis, dominaba en la estructura el grupo entre 16 y 40 años, es decir, que puede hablarse de una población joven en plena capacidad reproductiva y que actúa de manera positiva en el desarrollo demográfico, lo que permitió mantener la población en niveles casi estables, o con ligeros aumentos, a pesar de que durante la últimas tres décadas del siglo XVIII Caracas venía padeciendo fuertemente los efectos de las enfermedades infecto-contagiosas, que desde el siglo anterior azotaban a la población a causa del atraso de la medicina y las bajas condiciones sanitarias.

De la misma manera localizamos la matrícula de la parroquia Altagracia, del mismo año, con las mismas especificaciones. ${ }^{17}$ No se localizaron otros datos similares correspondientes a las demás parroquias, por lo que no se pudo obtener el total de la población de Caracas en 1807, por edades, sexo y grupos étnico-sociales. Sin embargo, la información obtenida fue de gran utilidad en el establecimiento de comparaciones de relaciones de la estructura demográfica.

17 Ibídem. Caracas-Altagracia, núm. 2. Matrícula de la Parroquia de Altagracia. Año 1807, fol. 705. 
IV) Estas fuentes están al alcance del investigador sin limitación alguna en el Archivo Arquidiócesano de Caracas. Incluyen toda la documentación de las 205 parroquias eclesiásticas que constituían el Obispado de la Provincia de Venezuela.

\section{La población de Caracas, 1772-1820. Ocupación física del espacio urbano y comportamientos}

En atención a la documentación trabajada, complementada con otro tipo de fuente - con todas las limitaciones del caso- precisaremos dos aspectos fundamentales: la ocupación física del espacio urbano y su dinámica y las características de la estructura demográfica y el comportamiento de la población, ante determinadas condiciones socio-económicas y culturales.

Estudiar el marco físico-espacial de Caracas nos lleva a determinar a través del enfoque geohistórico, momentos o períodos fundamentales, tomando en cuenta los elementos o factores que intervienen en el proceso social y de desarrollo urbano.

La ciudad de Santiago de León de Caracas, fundada por don Diego de Losada en 1567, se situó geográficamente al noroeste de un estrecho valle longitudinal enmarcado, de oeste a este, por las quebradas: Caroata y Catuche, seguidas éstas por la de Anauco. Al norte, la gran montaña del Avila, de donde se desprenden las quebradas ya mencionadas. Por el sur, el río Guaire, donde desembocan. ${ }^{18}$

En lo que respecta a la estructura urbana, la ciudad adoptó el modelo clásico impuesto por los españoles en América, para lo cual se habían dictado normas precisas por parte de la Corona. ${ }^{19}$ La planta de la ciudad siguió el trazado del plano cuadricular o damero formado por elementos iguales,

18 Mago de Chópite, Lila: Caracas y su..., pág. 46.

19 Los antecedentes de estas normas se hallan en los textos de las Instrucciones otorgadas a Nicolás de Obando en 1501, a Pedrarias Dávila en 1513, a Cortés en 1523 y en las Ordenanzas de Carlos $V$ en 1526. Estas disposiciones legales sirvieron de base a la famosas Ordenanzas de Felipe II firmadas en Segovia el 13 de julio de 1573, que sentaron las bases definitivas del urbanismo en todas las ciudades hispanoamericanas fundadas después de su elaboración. Caracas ya había sido fundada antes de que se publicaran las ordenanzas de Segovia, sin embargo, el espíritu y antecedentes de esta legislación ya estaban contenidos en el plano y estructura de la ciudad, que indudablemente en tiempos del gobernador Pimentel (1576-1583), se ratificaron. Ibídem, pág. 48. 
uno de los cuales servía de Plaza Mayor. Alrededor de la misma se agrupaban la Catedral o Iglesia Mayor, el Palacio Episcopal, el Ayuntamiento o Cabildo y demás dependencias del gobierno civil y político. De los cuatro ángulos de la Plaza Mayor salían las calles principales, cuatro de norte a sur y cuatro de este a oeste, perfectamente alineadas, sobre las cuales se distribuían las manzanas o solares, destinadas a las construcciones de las viviendas en orden jerárquico; primero las autoridades coloniales y después los vecinos. ${ }^{20}$ Estas calles se prolongaban y terminaban en los caminos principales que daban salida a la ciudad, ofreciendo la posibilidad de que continuaran en la medida en que Caracas crecía.

Sus elementos esenciales quedaron definidos desde el comienzo del siglo XVII, y así permanecieron a lo largo del siglo XVIII, con muy pocas alteraciones en cuanto a cambios sustanciales en su estructura física y monumental.

No tuvo Caracas grandes conjuntos urbanos ni obras trascendentales de diseños arquitectónicos. José de Oviedo y Baños destaca con singular atención la arquitectura eclesiástica en Caracas durante el siglo XVII. Los detalles arquitectónicos más notables de la catedral caraqueña durante el siglo XVII eran:

"Su fábrica se forma en cinco naves, cuya techumbre carga sobre pilares de ladrillo, con arcos de lo mismo; y aunque cada nave de por sí es algo angosta, todas juntas disponen una obra muy vistosa en proporción simétrica: el presbiterio es de bóveda, y de forma en el crucero con los primores de la arquitectura á lo moderno una media naranja bien airosa.

"Fuera de las cinco naves adornan su edificio cuatro capillas de particulares patronatos que unidas al lado de la epístola forman otra nave separada". ${ }^{21}$

Las cuatro capillas particulares correspondían a la Santísima Trinidad, otra donde se veneraba el Portento de los Milagros, San Nicolás de Bari, la de Nuestra Señora del Pilar de Zaragoza y la de Nuestra Señora del Pópulo.

La ciudad contaba con los servicios de tres ayudas de parroquias: la dedicada a Nuestra Señora de Altagracia, fundada por mulatos que cuidaban de su asistencia, aseo y ornato; la dedicada a San Pablo Primer Ermitaño, convertida en Hospital en ocasión de una peste de viruela que diezmó la mitad de los indios de la Provincia; y, por último, la de Nuestra

20 Ibídem.

21 Oviedo y Baños, José de: Historia de la Conquista y Población de la Provincia de Venezuela. Caracas, 1967, págs. 422-423. 
Señora de la Candelaria, extramuros de la ciudad — la más moderna- edificada por los naturales de las Islas Canarias. ${ }^{22}$

Estas tres ayudas de parroquias fijaron las bases para la creación de las parroquias Nuestra Señora de Altagracia, San Pablo y la de Nuestra Señora de la Candelaria, que conjuntamente con la Catedral formaron las cuatro parroquias eclesiásticas que dieron unidad al paisaje urbano caraqueño, como ya se ha indicado. El crecimiento de la parroquia San Pablo originó una nueva parroquia, Santa Rosalía, en la medida en que la ciudad se expandía y crecía en distintas direcciones por efecto de los cambios demográficos.

En el año 1708 se creó la ermita de Santa Rosalía, cerca de la de San Pablo, distante de ésta unas 4 ó 5 cuadras, prestando servicios religiosos a los habitantes que residían en el campo y que constituían uno de los sectores más pobres de la ciudad. En 1777 se erigió en ayuda de parroquia; y en 1779 fue autorizada por el rey para que se erigiera en parroquia separada de la de San Pablo. ${ }^{23}$

Durante el siglo XVIII la ciudad crecía hacia el oeste, hacia el norte, y algo hacia el este. Las numerosas viviendas, desde las más lujosas, pertenecientes a la aristocracia terrateniente, fabricadas bajo el sistema de tapias y con materiales traídos desde España por la Compañía Guipuzcoana, hasta las más humildes fabricadas con bahareque — sistema que utilizaron los indios y que fue adoptado por los españoles - emplearon la teja para los techos y ladrillos para los pisos. Estos dos últimos elementos se convirtieron en materiales básicos para la construcción de viviendas, encontrándose en abundancia la tierra apropiada para su elaboración en diversos lugares de la ciudad, especialmente en la zona del río Caroata, donde se establecieron las instalaciones productivas más importantes: hornos de cal, de ladrillo, tejerías, canteras, mataderos, tenerías, carnicerías, etc.

El progreso de la ciudad se manifestaba, sobre todo, en las mejoras de las viviendas y en el aumento de éstas en la periferia, debido principalmente al gran número de pardos libres y negros libres, así como de algunos indios que establecieron allí su residencia.

En Caracas la diferenciación social se manifestaba en la vida urbana, en cuanto a la organización de la ciudad y en la construcción de la vivienda. En la zona central, después de la Plaza Mayor, se residenciaban en las

22 Ibídem, págs. 425-426.

23 Según documento localizado en el AAC, Parroquiales, núm. 42. Año 1777. Véase en Mago de Chópite: Caracas y su..., págs. 179-185. 
cuadras principales las familias del estrato más alto de la sociedad colonial y demás sectores importantes, cuyas viviendas sobresalían con respecto a las demás por la decoración de sus portales y la calidad y solidez de los materiales de construcción.

La zona intermedia, inmediata a la central, albergaba numerosas viviendas y edificios religiosos, los cuales se ubicaban cada dos o tres cuadras en correspondencia con los caminos principales de salida de la ciudad. El intenso mestizaje habitaba la periferia, principalmente el sur hacia el río Guaire, y al oeste en las riberas del río Caroata.

Sin embargo, en la Matrícula de la Parroquia Catedral del año 1774 puede observarse que la periferia no fue siempre asiento de los desposeídos: ${ }^{24}$ también se encontraban allí las estancias o haciendas, habitadas por sus dueños y familiares.

En el sitio de Catia aparecen empadronadas tres estancias: la de don Beltrán de Masa, donde vivía con su mujer y dos personas más; la de don Salvador Madrid, habitada por él y dos indios; y la estancia de don Manuel Madrid, ocupada además de él por otra persona (no se especifica su posición social ni parentesco), y un indio. En los linderos encontramos la casa de Francisco Fuenmaron, de condición pardo libre, casado, que vivía con su mujer y cinco hijos. En Tipe, también en la periferia, se ubicaban cuatro casas más de personas de condición muy humilde. ${ }^{25}$

Desde mediados del siglo XVIII, según testimonios de las matrículas parroquiales y el que nos dejó el obispo Mariano Martí, la Iglesia dividió la ciudad en las cuatro parroquias ya mencionadas. Los pueblos que rodeaban el valle de Caracas, bajo la jurisdicción de la Iglesia — Chacao, La Vega, Antímano, La Guaira y el de Valle de la Pascua- mantenían con la ciudad estrechas relaciones comerciales. Estos contactos aumentaron en la medida en que Caracas crecía en sus límites urbanos por efecto de los cambios demográficos que originó el incremento del consumo interno.

Caracas, convertida en residencia de los grandes propietarios tanto del valle como de sus alrededores - algunos ausentistas cuyas riquezas provenían de las plantaciones de cacao producto del trabajo de los esclavos y otras categorías serviles-, se transformó en el centro financiero más importante de este producto. La comercialización del cacao la abre a la exportación a través del Puerto de La Guaira. Los beneficios obtenidos en

24 AAC, Matrículas Parroquiales. Caracas-Catedral. Matrícula de la Parroquia Catedral Oriente, fols. 1-87.

25 Ibídem. 
las transacciones se vertían en sus haciendas y en la construcción de casonas coloniales donde fijaron su residencia con algunos esclavos y sirvientes. Su proximidad con los centros de producción agrícola y pecuaria más importantes, la necesidad de mayor abastecimiento y su rango de capital de la provincia, la convierten en mercado y centro de decisiones políticas más importantes y, en general, de la administración colonial, con residencia obligada de la burocracia administrativa y eclesiástica. Residen en ella el gobernador y capitán general y el resto de los funcionarios con jurisdicción en los asuntos civiles, políticos, administrativos y judiciales; residen también el obispo y demás funcionarios del estado eclesiástico. Esta población se incluía en la categoría de blancos europeos y blancos americanos.

Organizados los datos de las matrículas por parroquias, se nos facilitó la tarea de totalizar la población de Caracas en algunos años: 1772, 1792, $1802,1804,1811$ y 1815 . Partiendo de esta información podemos comprobar las tendencias en el ritmo de crecimiento de la población entre 1772 y 1815. La discriminación de los datos nos permitió partir del año 1772 con la información que nos dejó el obispo Martí que contenía el número de habitantes de las cuatro parroquias eclesiásticas, cuyo total asciende a 18.669 habitantes (cuadros 1 y 2).

En el cuadro 2, elaborado con los asientos hechos en las matrículas parroquiales de ese mismo año, el total ascendió a 18.628 habitantes. En 1792 la población de Caracas, según el total de todas las parroquias, era de 28.362. Veinte años después del censo del obispo Martí hubo un aumento de 9.693 habitantes (cuadro 3).

En 1802, diez años después, la población ascendió a 29.392 personas, distribuidas por grupos de la siguiente manera: blancos $9.438(32.11 \%)$, indios 470 (1.60\%), pardos libres 11.399 (38.78\%), negros libres 1.631 (5.75\%), esclavos 6.169 (20.99\%) eclesiásticos 225 (0.77\%) (cuadro 4). Como puede observarse, los pardos libres eran más que los blancos; los esclavos ocupan un lugar significativo, y por último los negros libres e indios en minoría. Es de advertir que a partir de 1782 los datos en los totales aparecen discriminados por grupos étnico-sociales y así continúan apareciendo en el resto de los años correspondientes al período estudiado.

En el año 1804 el total de habitantes era de 30.708. Aumentó en 1.319 habitantes en dos años. La estructura por grupos cambió en poca proporción en relación a la de 1802: blancos 10.899 (35.48\%), indios 485 (1.58\%), pardos libres 11.594 (37.76\%), negros libres $1.383(4.50 \%)$, esclavos 6.226 (20.77\%), eclesiásticos 121 (0.39\%) (cuadro 5). 


\section{LILA MAGO DE CHÓPITE}

Hasta la última fecha señalada, podemos apreciar en la estructura de la población, con muy pocas alteraciones, el dominio de los pardos sobre los blancos en todas las parroquias estudiadas; y si agregamos el número de negros (libres y esclavos) e indios, a los pardos, en total hacen la mayoría de la población en relación a los blancos.

En 1811 se observan cambios en el comportamiento de la población. Según los registros ésta llegó a 30.427. Disminuyó en 281 habitantes en relación a 1804. La distribución por grupos era la siguiente: blancos 9.608 (31.58\%), indios 590 (1.94\%), pardos libres 11.539 (37.93\%), negros libres 2.351 (7.73\%), esclavos 6.100 (20.05\%), eclesiásticos 239 (0.79\%). Los blancos disminuyen de 10.899 en 1804 a 9.608; los otros grupos sociales se mantienen con poca diferencia; los esclavos permanecen en una proporción bastante considerable, si se tiene en cuenta que en el año 1811 la población disminuyó (cuadro 6).

En 1815 la situación anterior se acentuó. La tendencia es a bajar considerablemente el número de habitantes. De 30.427 en 1811 bajó a 19.509 . La población disminuyó en 10.918 habitantes. La distribución por grupos quedó así: blancos 6.032 (30.92\%), indios 572 (2.93\%), pardos libres 7.045 (36.11\%), negros libres 1.295 (6.64\%), esclavos 4.475 (22.99\%), eclesiásticos $90(0.46 \%)$.

De acuerdo al análisis de los datos se observa, en relación a 1811, una progresiva tendencia a disminuir la población; lentamente a partir de 1811 , para luego acentuarse considerablemente en 1815.

Para 1812, Caracas sufrió un devastador terremoto que ocasionó innumerables pérdidas humanas. Paralelamente a este fenómeno natural, la población se vio afectada negativamente a causa de los sucesos desencadenados por la Guerra de Independencia. Todos estos factores, unidos al abandono de las actividades productivas en el campo, el deterioro de las condiciones de vida, la baja producción agrícola y pecuaria, las migraciones por razones políticas, la miseria, las epidemias y las bajas condiciones sanitarias, afectaron el desarrollo de las relaciones sociales y el crecimiento demográfico (cuadro 7).

En síntesis, el estudio de los datos nos llevó a establecer tentativamente dos tendencias en el crecimiento de la población de Caracas entre 1772 y 1815 .

I) Entre 1772 y 1802 la población se mantuvo más o menos estable, con un crecimiento lento. A partir de 1802 se inicia un proceso de recupe- 
ración en casi todas las parroquias estudiadas, tendencia que se acentuó en el transcurso de esta primera década del siglo XIX.

II) Entre 1810 y 1815 la población descendió notablemente, con pérdida de 10.918 habitantes. Las causas de este deterioro demográfico pueden atribuirse a dos hechos fundamentales que afectaron notablemente la sociedad caraqueña: el terremoto de 1812 y los sucesos que condujeron a la Guerra de Independencia.

En cuanto a la distribución por grupos étnico-sociales, durante todo el período en estudio se mantuvo el dominio de los pardos sobre los blancos, lo cual nos permitió establecer como rasgo dominante de la estructura demográfica de la población colonial la existencia mayoritaria de los pardos sobre los otros grupos sociales.

El número de esclavos se mantuvo en forma significativa, por encima de los 6.000, algo más de una cuarta parte de la población, con excepción del año 1815 en que disminuyó en términos absolutos, aunque en términos relativos se mantuvo en el mismo nivel. En menor proporción se mantuvieron los negros libres y, por último, los indios.

Difícilmente podemos llegar a conclusiones de carácter definitivo en este trabajo; pensamos que, en el futuro, la ejecución de las otras etapas del proyecto nos llevará a confirmar o a rebatir lo que en principio hemos afirmado.

El trabajo del historiador conlleva estos riesgos. De modo que asumimos el compromiso de continuar en la indagación del tema que nos interesa. En este caso concreto, tal como nos enseña Marc Bloch, el trabajo sobre los documentos no solamente está sujeto a los errores de la subjetividad del investigador, sino que también hay que tener en cuenta, "Su presencia o su ausencia, en tales o cuales archivos, en una u otra biblioteca, en el suelo, dependen de causas humanas que no escapan al análisis, y a los problemas que plantea su transmisión, lejos de tener únicamente el mero alcance de ejercicios técnicos, rozan lo más íntimo de la vida del pasado, porque lo que se encuentra así puesto en juego es nada menos que el paso del recuerdo a través de las generaciones". ${ }^{26}$

Asumimos los riesgos persuadidos de que, "El espectáculo de la investigación, con sus éxitos y fracasos, no es casi nunca aburrido. Lo acabado es lo que destila pesadez y tedio". ${ }^{27}$

26 Bloch, Marc: Introducción a la Historia. México, 1974, pág. 59.

27 Ibídem. 


\title{
Cuadros y gráficos
}

\author{
CUAdro 1 \\ MATRÍCULA O PADRONES DE LOS HABITANTES DE LAS CUATRO \\ PARROQUIAS DE ESTA CIUDAD DE CARACAS FORMADA POR SUS \\ RESPECTIVOS CURAS A CONSECUENCIA DE LA RAZÓN QUE \\ A CADA UNO SE LE PIDIÓ LUEGO QUE FUERON \\ VISITADAS SUS IGLESIAS EL AÑO 1772
}

\begin{tabular}{lrrrrrrrrr} 
& \multicolumn{1}{c}{$\begin{array}{c}\text { Personas de De sola } \\
\text { Feligresías }\end{array}$} & Casas Familias Sacerdotes & comunión & confes. Párvulos & Locos bozales & Totales \\
\hline De la Cathedral & 860 & 744 & 48 & 4.803 & 560 & 638 & 4 & 2 & 6.055 \\
De Ntra. Sra. de Altagracia & 429 & 488 & 8 & 2.194 & 402 & 604 & 8 & 2 & 3.218 \\
De Ntra. Sra. de la Candelaria & 439 & 431 & 3 & 1.661 & 442 & 776 & 2 & 3 & 2.887 \\
De San Pablo & 1.081 & 1.046 & 19 & 4.451 & 875 & 1.152 & 4 & 8 & 6.509 \\
\hline TOTALES & 2.809 & 2.709 & 78 & 13.109 & 2.279 & 3.170 & 18 & 15 & 18.669
\end{tabular}

Fuente: Archivo arzopispal de Caracas. Mariano Martí. Relación testimonio integro de la Visita general de este Obispado de Caracas y Venezuela. F1. 134.

\section{CuAdro 2}

CARACAS 1772

\begin{tabular}{llcc} 
& PARROQUIAS & NÚMERO DE HABITANTES & PORCENTAJE \\
\hline 1 & CATEDRAL ORIENTE & 3.230 & $17,34 \%$ \\
2 & CATEDRAL PONIENTE & 2.825 & $15,17 \%$ \\
3 & SAN PABLO & 6.509 & $34,94 \%$ \\
4 & CANDELARIA & 2.826 & $15,17 \%$ \\
5 & ALTAGRACIA & 3.238 & $17,38 \%$ \\
\hline & TOTALES & 18.628 & $100 \%$
\end{tabular}

CUADRO 3

CARACAS, 1792

\begin{tabular}{llcc} 
& PARROQUIAS & NÚMERO DE HABITANTES & PORCENTAJE \\
\hline 1 & CATEDRAL DE ORIENTE & 4.914 & $17,33 \%$ \\
2 & CATEDRAL PONIENTE & 3.781 & $13,33 \%$ \\
3 & SAN PABLO & 5.529 & $19,49 \%$ \\
4 & CANDELARIA & 4.290 & $15,13 \%$ \\
5 & ALTAGRACIA & 4.928 & $17,38 \%$ \\
6 & SANTA ROSALíA & 4.155 & $14,65 \%$ \\
7 & CURATO CASTRENSE & 765 & $2,70 \%$ \\
\hline & TOTALES & 28.362 & $100,00 \%$
\end{tabular}




\section{CuAdro 4}

CARACAS, 1802

Parroquias

Blancos Indios Pardos L. Negros L. Esclavos Eclesiásticos Totales

\begin{tabular}{|c|c|c|c|c|c|c|c|}
\hline 1 CATEDRAL ORIENTE & 1.422 & 75 & 1.351 & 284 & 1.560 & 54 & 4.746 \\
\hline 2 CATEDRAL PONIENTE & 1.036 & 89 & 1.171 & 150 & 1.029 & 48 & 3.523 \\
\hline 3 SAN PABLO & 1.905 & 98 & 2.493 & 438 & 1.353 & 45 & 6.332 \\
\hline 4 CANDELARIA & 1.308 & 86 & 1.348 & 282 & 514 & 17 & 3.555 \\
\hline 5 ALTAGRACIA & 1.774 & 42 & 2.528 & 537 & 893 & 37 & 5.811 \\
\hline 6 SANTA ROSALÍA & 1.683 & 77 & 2.508 & & 814 & 24 & 5.106 \\
\hline 7 CURATO CASTRENSE & 310 & 3 & & & 6 & & 319 \\
\hline TOTALES & 9.438 & 470 & 11.399 & 1.691 & 6.169 & 225 & 29.392 \\
\hline PORCENTAJE & 32,11 & 1,60 & 38,78 & 5,75 & 20,99 & 0,77 & 100,00 \\
\hline
\end{tabular}

Elaborado según datos del A. A. de C. por Lila Mago de Chópite.

\section{Cuadro 5}

CARACAS, 1804

Parroquias

Blancos Indios Pardos L. Negros L. Esclavos Eclesiásticos Totales

\begin{tabular}{llrrrrrrr}
\hline 1 & CATEDRAL DE ORIENTE & 1.524 & 50 & 1.620 & & 1.547 & & 4.741 \\
2 & CATEDRAL PONIENTE & 1.222 & 114 & 1.147 & 236 & 1.069 & & 3.788 \\
3 & SAN PABLO & 2.152 & 66 & 2.254 & 161 & 1.090 & 34 & 5.757 \\
4 & CANDELARIA & 1.343 & 73 & 1.331 & 322 & 504 & 18 & 3.591 \\
5 & ALTAGRACIA & 2.178 & 84 & 2.644 & 659 & 933 & 40 & 6.538 \\
6 & SANTA ROSALÍA & 1.586 & 92 & 2.541 & & 921 & 29 & 5.169 \\
7 & CURATO CASTRENSE & 894 & 6 & 57 & 5 & 162 & & 1.124 \\
\hline & TOTALES & 10.899 & 485 & 11.594 & 1383 & 6.226 & 121 & 30.708 \\
& PORCENTAJE & 35,49 & 1,58 & 37,76 & 4,50 & 20,77 & 0,39 & 100,00
\end{tabular}

Elaborado según datos del A. A. de C. por Lila Mago de Chópite. 


\section{CuAdro 6}

CARACAS, 1811

Parroquias

Blancos Indios Pardos L. Negros L. Esclavos Eclesiásticos Totales

\begin{tabular}{|c|c|c|c|c|c|c|c|}
\hline CATEDRAL ORIENTE & 1.383 & 36 & 1.554 & 193 & 1.432 & 52 & 4.650 \\
\hline CATEDRAL PONIENTE & 1.171 & 102 & 1.263 & 260 & 1.102 & 105 & 4.003 \\
\hline SAN PABLO & 1.350 & 239 & 1.930 & 800 & 1.011 & 29 & 5.359 \\
\hline A CANDELARIA & 1.290 & 41 & 1.275 & 301 & 432 & 20 & 3.359 \\
\hline ALTAGLACIA & 1.685 & 25 & 2.228 & 383 & 865 & 33 & 5.279 \\
\hline SANTA ROSALÍA & 1.727 & 140 & 3.161 & 377 & 1.065 & & 6.470 \\
\hline CURATO CASTRENSE & 1.002 & 7 & 128 & 37 & 193 & & 1.367 \\
\hline TOTALES & 9.608 & 590 & 11.539 & 2.351 & 6.100 & 239 & 30.427 \\
\hline PORCENTAJE & 31,58 & 1,94 & 37,93 & 7,73 & 20,05 & 0,79 & 100,00 \\
\hline
\end{tabular}

Elaborado según datos del A. A. de C. por Lila Mago de Chópite.

\section{Cuadro 7}

CARACAS, 1815

Parroquias

Blancos Indios Pardos L. Negros L. Esclavos Eclesiásticos Totales

\begin{tabular}{|c|c|c|c|c|c|c|c|}
\hline CATEDRAL ORIENTE & 788 & 27 & 849 & 58 & 636 & 21 & 2.379 \\
\hline CATEDRAL PONIENTE & 906 & 88 & 753 & 133 & 470 & 18 & 2.368 \\
\hline SAN PABLO & 1.478 & 289 & 2.250 & 520 & 2324 & 21 & 88 \\
\hline CANDELARIA & 854 & 67 & 893 & 301 & 282 & 11 & 40 \\
\hline ALTAGRACIA & 775 & 56 & 790 & 283 & 209 & & .11 \\
\hline SANTA ROSALÍA & 1.231 & 45 & 1.510 & & 54 & 19 & 3.35 \\
\hline CURATO CASTRENSE & & & & & & & \\
\hline TOTALES & 6.032 & 572 & 7.045 & 1.295 & 3.975 & 90 & 19.0 \\
\hline PORCENTAJE & 30,92 & 2,93 & 36,11 & 6,64 & 22,90 & 0,46 & 100 \\
\hline
\end{tabular}

Elaborado según datos del A. A. de C. por Lila Mago de Chópite. 


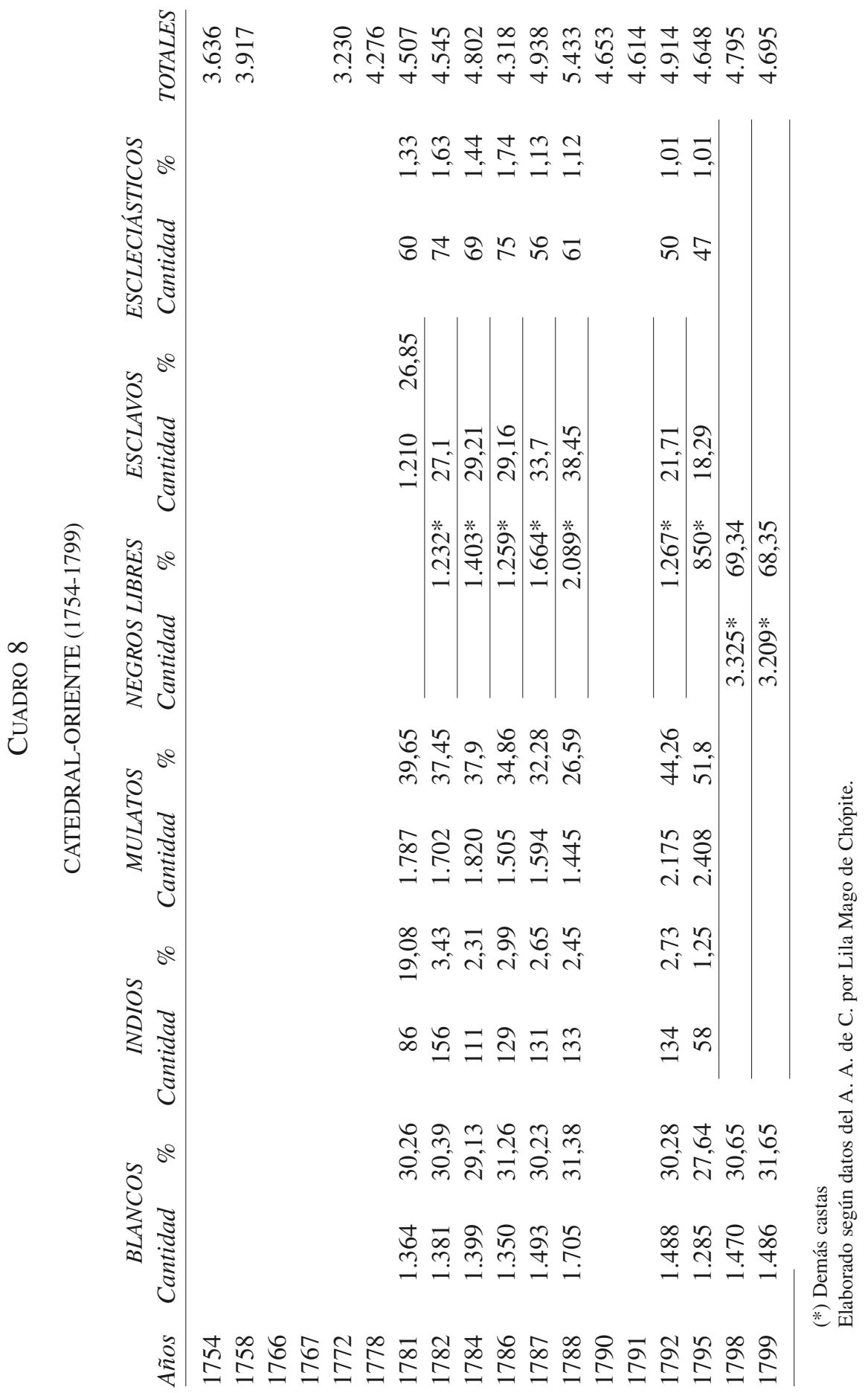




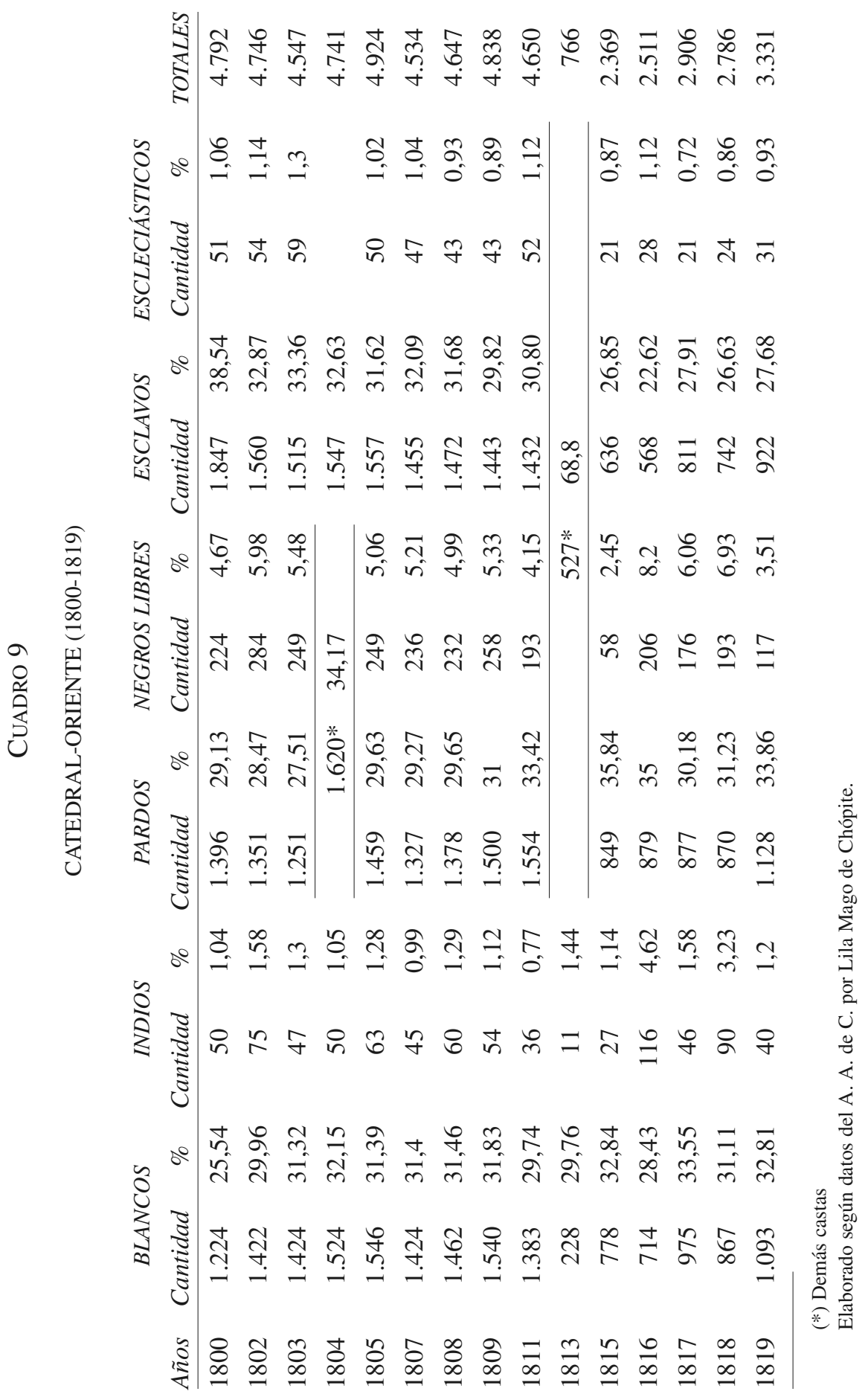




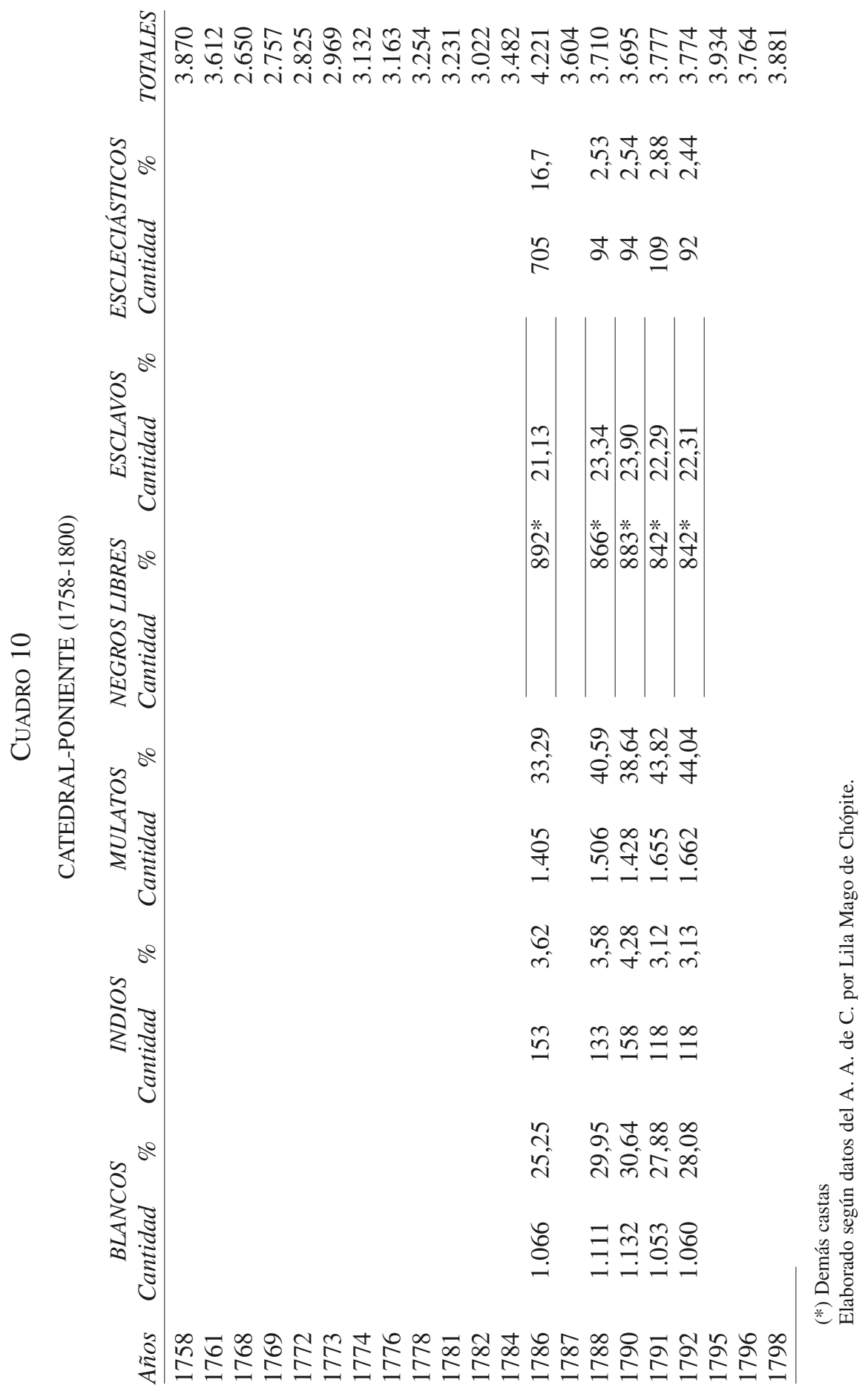




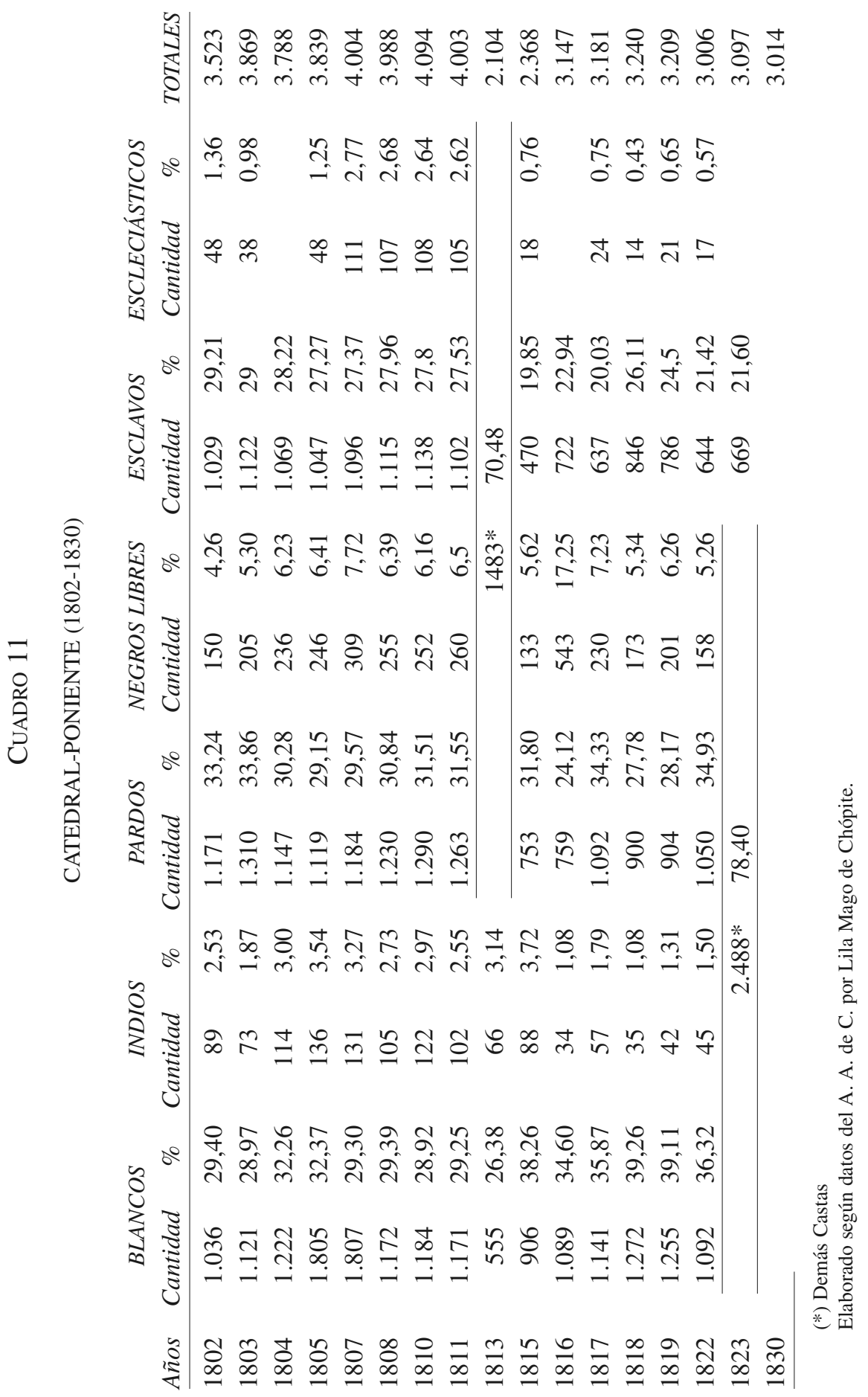




\section{LILA MAGO DE CHÓPITE}

\section{Población de CARACAS 1772}

Por parroquias urbanas

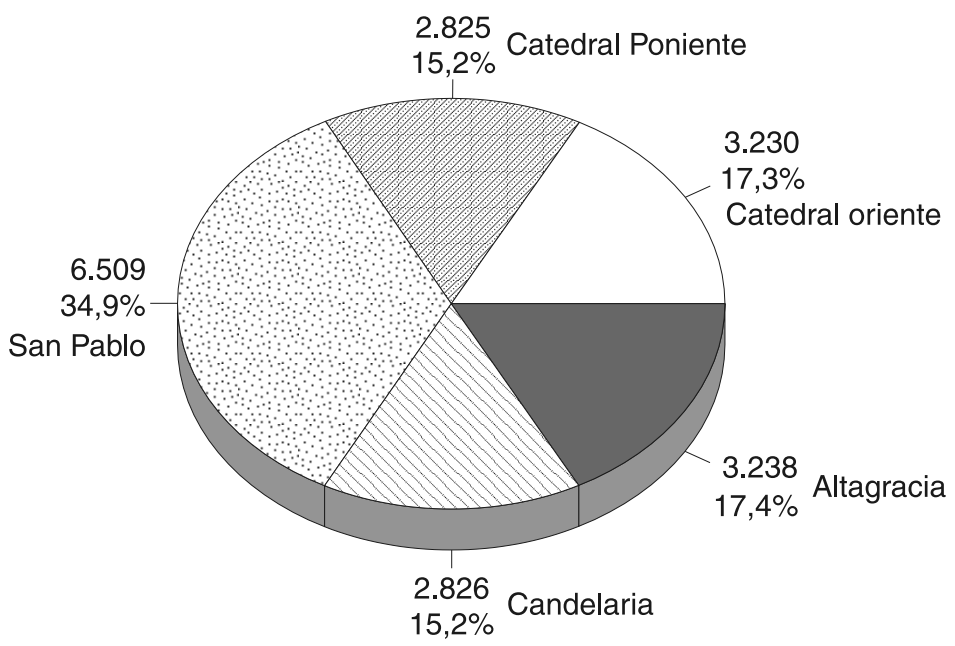

Elaborado según datos del A. A. de C. por Lila Mago de Chópite.

Población de CARACAS 1792

Por parroquias urbanas

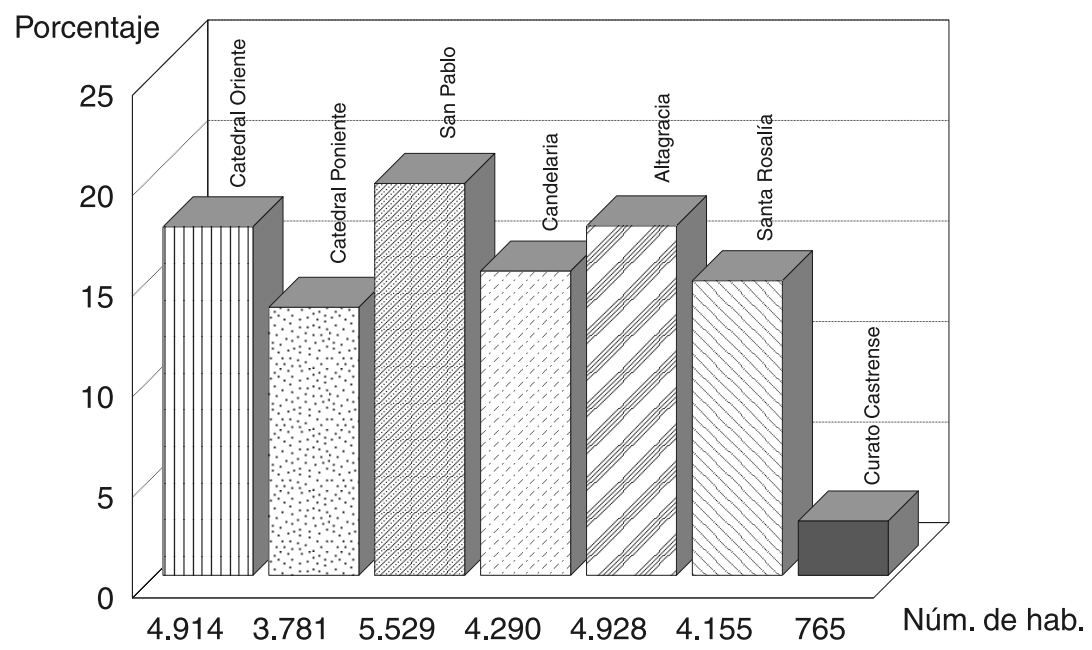

Elaborado según datos del A. A. de C. por Lila Mago de Chópite. 


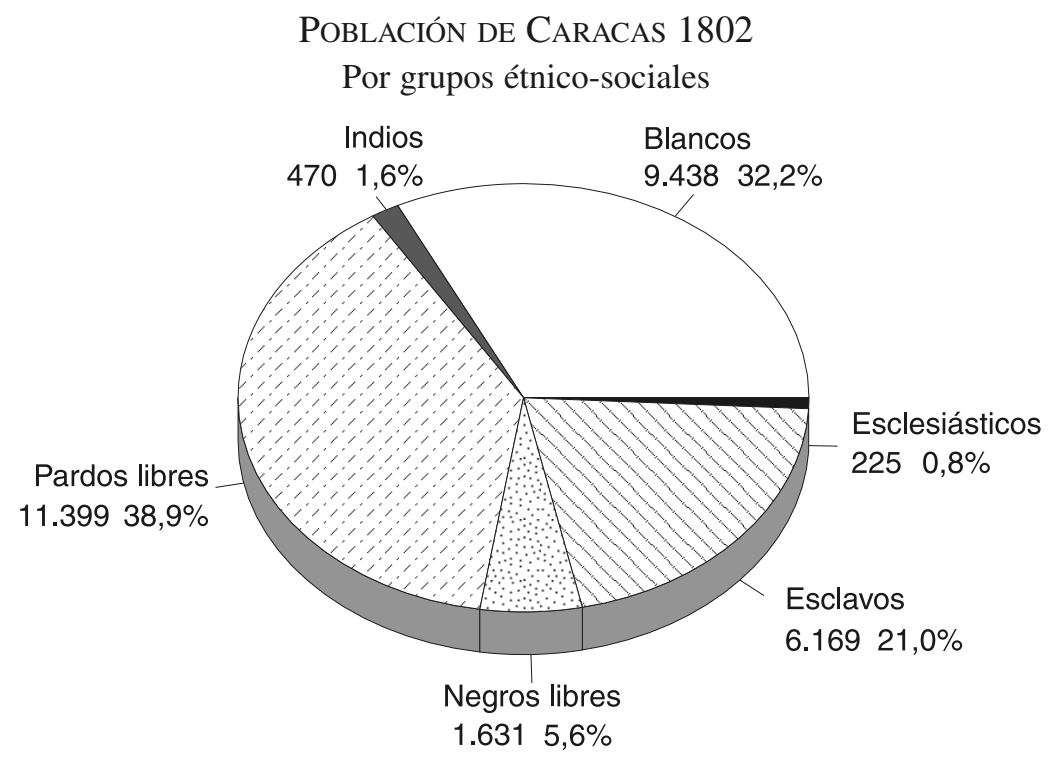

Elaborado según datos del A. A. de C. por Lila Mago de Chópite.

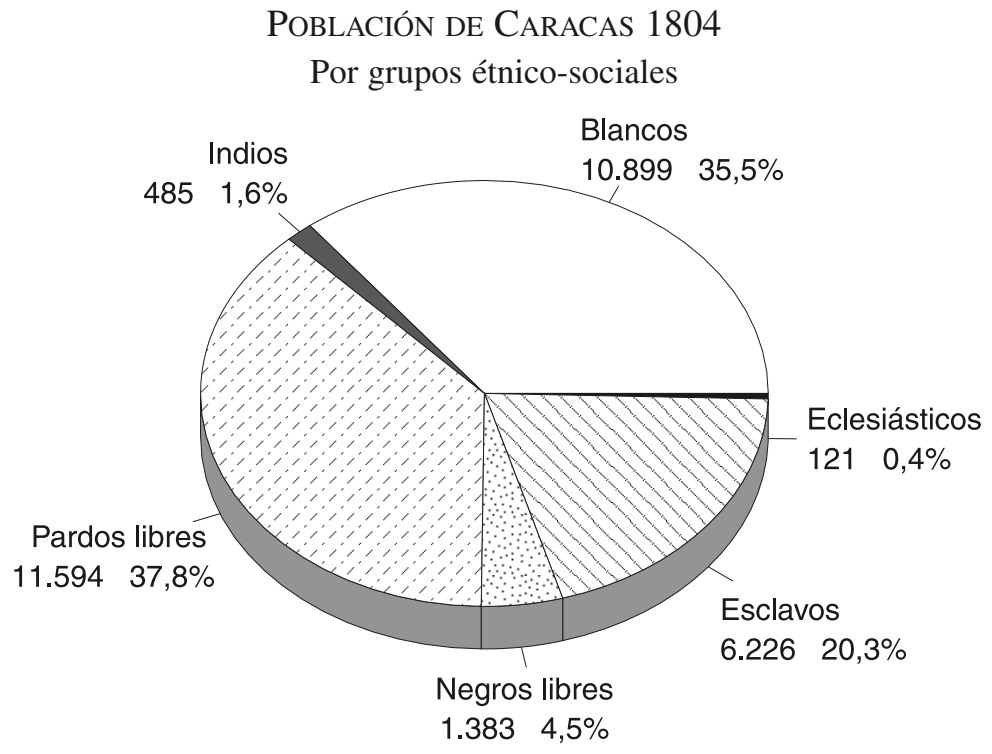

Elaborado según datos del A. A. de C. por Lila Mago de Chópite. 


\section{LILA MAGO DE CHÓPITE}

\section{Población DE CARACAS 1811}

Por grupos étnico-sociales

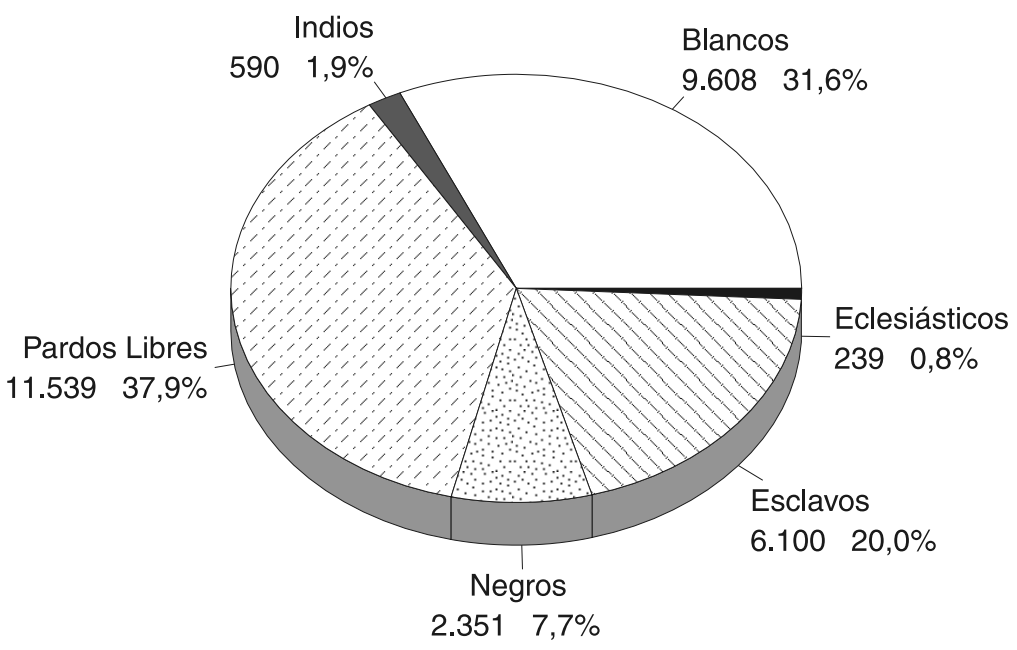

Elaborado según datos del A. A. de C. por Lila Mago de Chópite.

\section{Población de CARACAS 1815}

Por grupos étnico-sociales

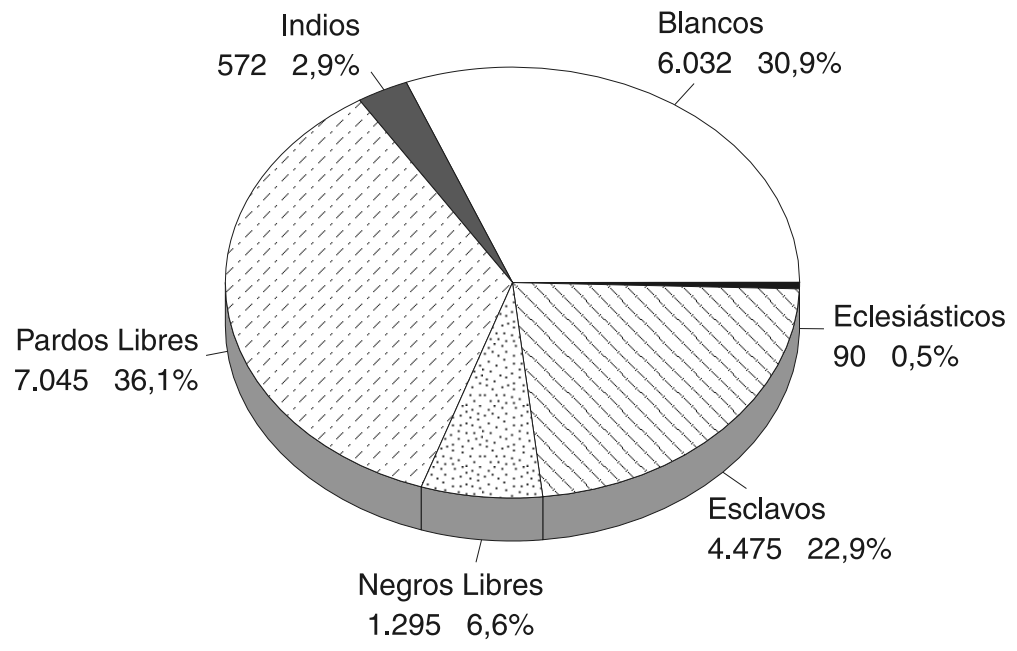

Elaborado según datos del A. A. de C. por Lila Mago de Chópite. 
GRÁFICO COMPARATIVO DEL CRECIMIENTO DE LA POBLACión DE CARACAS Años 1772-1815

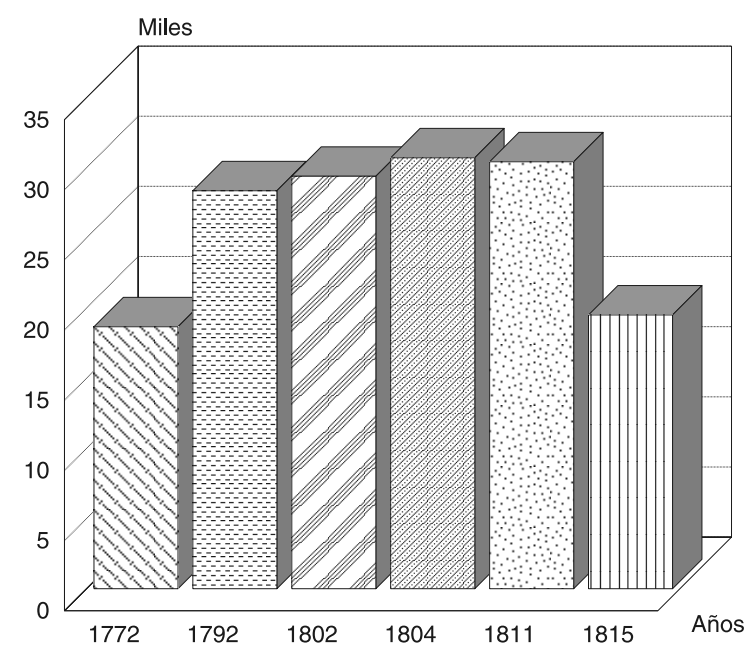

Elaborado según datos del A. A. de C. por Lila Mago de Chópite.

Población de CARACAS DE 1772 a 1815

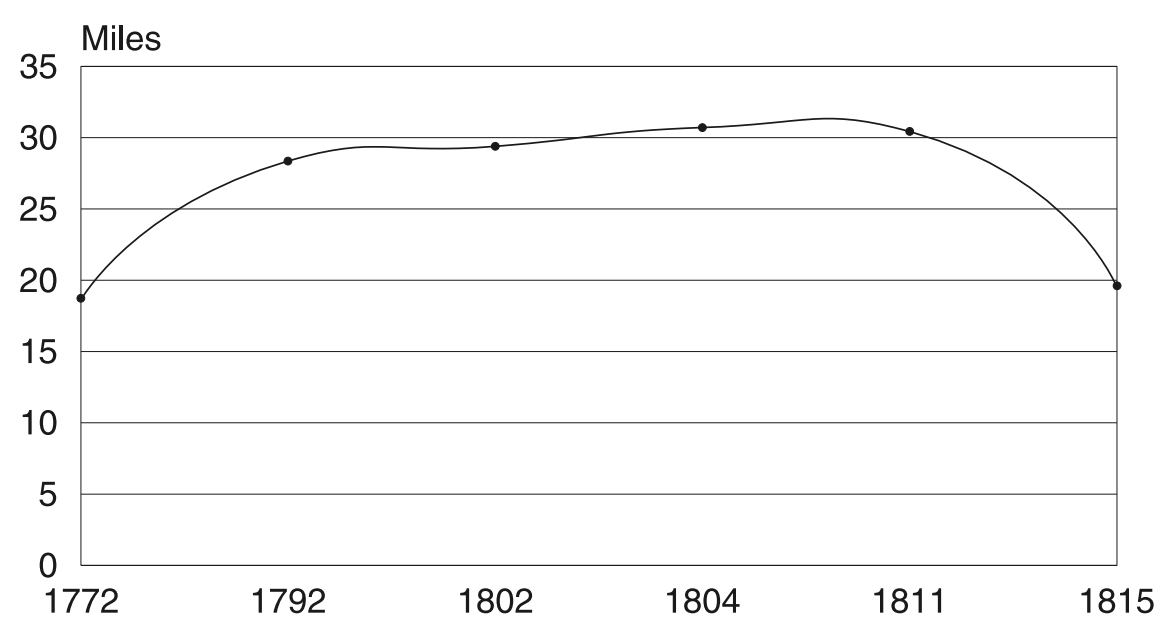

Elaborado según datos del A. A. de C. por Lila Mago de Chópite. 